\title{
Can a simple measure of vigorous physical activity predict future mortality? Results from the OXCHECK study
}

\author{
Melvyn Hillsdon ${ }^{1,2, *}$, Margaret Thorogood ${ }^{1}$, Mike Murphy $^{3}$ and Lesley Jones ${ }^{3}$ \\ 'Health Promotion Research Unit, London School of Hygiene \& Tropical Medicine, Keppel Street, London WC1E \\ 7HT, UK: ${ }^{2}$ Present address: Department of Epidemiology and Public Health, University College London, \\ 1-19 Torrington Place, London WC1E 6BT, UK: ${ }^{3}$ Cancer Research UK, General Practice Research Group, \\ Institute of Health Sciences, Old Road, Oxford OX3 7LF, UK
}

Submitted 9 June 2003: Accepted 8 0ctober 2003

\begin{abstract}
Background: As epidemiological studies have become more complex, demands for short, easily administered measures of risk factors have increased. This study investigates whether such a measure of physical activity is associated with the risk of death from all causes and death from specific causes.

Methods: A prospective follow-up study of 11090 men and women, aged 35-64 years, recruited from five UK general practices who responded to a postal questionnaire in 1989. Self-reported frequency of vigorous-intensity physical activity and data on confounding factors were collected at baseline survey. Death notifications up to 31 December 2001 were provided by the Office for National Statistics. The relative risk (and 95\% confidence interval) of dying associated with each level of exposure to physical activity was estimated by the hazard ratio in a series of Cox regression models.

Results: After $>10$ years' follow-up there were 825 deaths among the 10522 subjects with no previous history of angina or myocardial infarction. Participation in vigorous exercise was associated with a significantly lower risk of all-cause mortality. Similar associations were found for ischaemic heart disease and cancer mortality, although the relationships were not significant at the $5 \%$ level.

Conclusions: Simple measures of self-reported vigorous physical activity are associated with the risk of future mortality, at least all-cause mortality in a somewhat selected group. Interpretation of the finding should be treated with caution due to the reliance on self-report and the possibility that residual confounding may underlie the associations. Because moderate-intensity physical activity is also beneficial to health, short physical activity questionnaires should include measures of such physical activity in the future.
\end{abstract}

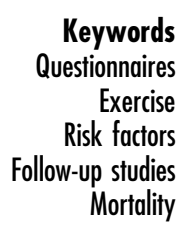

There is now a wealth of evidence linking physical inactivity to all-cause mortality and disease-specific mortality including ischaemic heart disease (IHD) and cancer ${ }^{1}$. Although physical inactivity represents a serious threat to health, few adults engage in health-protecting levels of physical activity. Just 37\% of men and 25\% of women are exercising at either of the current recommended levels, i.e. either 30 min of moderate-intensity physical activity on most - preferably all - days of the week, or 20 min of vigorous-intensity physical activity on at least 3 days of the week ${ }^{2}$.

As more is understood about risk factors for various chronic diseases, epidemiological studies have become more complex, resulting in lengthy questionnaires for data collection. Therefore, there is demand for short, easily administered measures of risk factors. This study investigates whether such a measure of vigorous-intensity physical activity is associated with the risk of death from all causes and death from specific causes. To do this, analysis was undertaken of a prospective study of over 11000 participants, in a British primary care setting, with more than 10 years' follow-up to 2001.

\section{Methods}

\section{Subjects}

All participants who provided baseline data for the OXCHECK trial made up the study population. The OXCHECK trial was a randomised controlled trial of nurse health checks in primary care, details of which have been described elsewhere ${ }^{3}$. Briefly, in 1989, questionnaires were posted to all 17965 patients registered with five urban practices around Luton and Dunstable (Bedfordshire, UK) who were aged 35-64 years on 1 January 1989. Of these, 
338 were ineligible to participate and 3810 were subsequently found to have died or no longer lived at the address recorded by their registered practice. Following three mailings, 11090 patients returned baseline questionnaires, of whom 8109 subsequently participated in the OXCHECK trial. Data are presented for 10522 participants without a history of chest pain who completed baseline questionnaires as well as 7704 of those participants, without a history of chest pain, who attended a health check with a nurse as part of the OXCHECK trial.

\section{Measures}

Data were collected via self-completion questionnaire and provided information on occupation, education, self-rated health, smoking, alcohol consumption and diet. Social class was assigned according to the Occupational Classifications of the Office of Population Censuses and Surveys ${ }^{4}$. In addition, respondents completed a series of validated questions to identify those with angina or a past possible myocardial infarction $(n=568)$. Participants were asked about the frequency of participation in vigorous sports or recreational activities that made them out of breath, such as jogging, aerobics, football, tennis, etc. The baseline and supplementary (interview) questions on physical activity are shown in the Appendix. The nature of the questions on physical activity in the baseline questionnaire made deriving suitable categories for analysis difficult. Too few participants reported vigorous exercise more than three times a week to produce meaningful analysis and as a consequence it was necessary to collapse the four categories. It was felt that participants who exercised two or three times per week would most likely assign themselves to the third category and those doing vigorous exercise once per week would assign themselves to the second category. Therefore three categories were derived: (1) never/ $<1$ time per month; (2) $<2$ times per week; (3) $\geq 2$ times per week.

The subset of 7704 participants who attended a nurse health check were asked supplementary questions about the frequency of participation in vigorous exercise. Respondent's height and weight were elicited, allowing body mass index (BMI) to be derived by dividing the weight in kilograms by the square of their height in metres.

\section{Follow-up}

All respondents to the 1989 postal survey were 'flagged' with the Office for National Statistics National Health Service Central Register (ONS NHSCR) for continuous follow-up for mortality, underlying cause of death coding according to the International Classification of Diseases (ICD) editions in force (9 and now 10) and cancer incidence. For the analyses in this paper, deaths were assigned to mutually exclusive categories, namely IHD (ICD-9 codes 410.0-414.9) and all neoplasms (ICD-9 codes 140.0-239.9).

\section{Analysis}

The relative risk (and 95\% confidence interval) of dying associated with each level of exposure to physical activity was estimated by the hazard ratio in a series of Cox regression models. Relative risks were separately estimated for all-cause mortality, IHD mortality and mortality from any cancer. The person-time contribution of each participant was calculated from the date of return of the questionnaire until the date of death, or until 31 December 2001 for surviving participants.

Physical activity exposure was analysed as a categorical variable with data for frequency of participation in vigorous physical activity grouped as 'never $/<1$ time per month', ' $<2$ times per week' and ' $\geq 2$ times per week'.

Physical activity exposure for the 7704 health check attendees was categorised into slightly different categories: ' $<1$ time per month', ' $1-3$ times per month', ' 1 time per week' and ' $\geq 2$ times per week'.

Participants with a prior history of angina or myocardial infarction may have modified their physical activity prior to baseline data collection and were therefore excluded from physical activity analyses. The remaining 10522 participants reported no previous episodes of chest pain. Confounding was controlled for through the inclusion of design variables in multivariate Cox regression analyses. All analyses were conducted in PROC PHREG of SAS version 6.12 (SAS Institute, Cary, NC, USA, 1996).

\section{Results}

Crude relative risks of the baseline distributions of nonphysical activity exposures are presented in Table 1. Age at entry, current smoking status, the presence of longstanding illness and low social class were all strong predictors of future mortality. Although a greater BMI appeared to increase the risk of IHD death, the elevation in risk was not significant at the 5\% level. Females had a significantly lower risk of future mortality from all causes and IHD compared with males, while the difference in cancer mortality was not significant. Those participants in the postal survey who subsequently attended for a health check in the OXCHECK trial had a significantly reduced risk of future mortality compared with those who did not. Light alcohol intake $(<21$ units per week for males and $<16$ units for females) was associated with a significant reduction in risk of future mortality compared with abstaining from alcohol. Participants with higher alcohol intakes did not have a significantly lower risk of future mortality compared with participants who abstained.

For those participants with no history of chest pain at the time of completing the postal questionnaire, the adjusted relative risks of death associated with different self-reported physical activity levels are presented in Table 2. Participation in vigorous exercise was associated with a significantly lower risk of all-cause mortality and the same relationship was apparent for IHD and cancer 
Table 1 Distribution of established risk factors at baseline among participants with no previous history of angina $(n=10522)$, and crude relative risk (RR) and 95\% confidence interval $(\mathrm{Cl})$ of death from all causes and from specific causes, associated with levels of exposure

\begin{tabular}{|c|c|c|c|c|c|c|c|c|}
\hline & \multirow[b]{2}{*}{$n$} & \multirow[b]{2}{*}{$\%$} & \multicolumn{2}{|c|}{ All causes } & \multicolumn{2}{|c|}{$\begin{array}{c}\text { Ischaemic } \\
\text { heart disease }\end{array}$} & \multicolumn{2}{|c|}{ Cancer } \\
\hline & & & $\mathrm{RR}$ & $(95 \% \mathrm{Cl})$ & $\mathrm{RR}$ & $(95 \% \mathrm{Cl})$ & $\mathrm{RR}$ & $(95 \% \mathrm{Cl})$ \\
\hline \multicolumn{9}{|l|}{ Sex } \\
\hline Male & 4929 & 46.8 & 1.00 & & 1.00 & & 1.00 & \\
\hline Female & 5593 & 53.2 & 0.67 & $(0.59-0.77)$ & 0.41 & $(0.30-0.56)$ & 0.83 & $(0.68-1.02)$ \\
\hline \multicolumn{9}{|l|}{ Age group (years) } \\
\hline $35-44$ & 4035 & 38.4 & 1.00 & & 1.00 & & 1.00 & \\
\hline $45-54$ & 3418 & 32.5 & 3.20 & $(2.49-4.13)$ & 3.08 & $(1.62-5.85)$ & 4.12 & $(2.78-6.11)$ \\
\hline $55-64$ & 3069 & 29.2 & 9.92 & $(7.87-12.51)$ & 16.02 & $(9.08-28.3)$ & 9.90 & $(6.84-14.3)$ \\
\hline \multicolumn{9}{|l|}{ Smoking } \\
\hline Never & 4089 & 38.9 & 1.00 & & 1.00 & & 1.00 & \\
\hline Ex-smoker & 3175 & 30.2 & 1.79 & $(1.49-2.15)$ & 3.00 & $(1.93-4.68)$ & 2.05 & $(1.56-2.69)$ \\
\hline Pipe/cigar & 533 & 5.1 & 2.73 & $(2.08-3.59)$ & 4.53 & $(2.45-8.38)$ & 2.25 & $(1.43-3.55)$ \\
\hline Cigarettes $<15$ day $^{-1}$ & 839 & 8.0 & 2.64 & $(2.08-3.35)$ & 6.18 & $(3.75-10.19)$ & 2.05 & $(1.38-3.06)$ \\
\hline Cigarettes $15-24$ day $^{-1}$ & 1335 & 12.7 & 2.37 & $(1.92-2.93)$ & 3.74 & $(2.26-6.19)$ & 2.33 & $(1.68-3.24)$ \\
\hline Cigarettes $\geq 25$ day $^{-1}$ & 539 & 5.1 & 2.58 & $(1.95-3.41)$ & 4.20 & $(2.24-7.86)$ & 2.41 & $(1.55-3.75)$ \\
\hline \multicolumn{9}{|l|}{ Long-standing illness } \\
\hline No & 6992 & 67.6 & 1.00 & & 1.00 & & 1.00 & \\
\hline Yes & 3355 & 32.4 & 2.39 & $(2.09-2.73)$ & 2.95 & $(2.20-3.95)$ & 1.82 & $(1.48-2.24)$ \\
\hline \multicolumn{9}{|l|}{ Participation in OXCHECK } \\
\hline No & 2744 & 26.3 & 1.00 & & 1.00 & & 1.00 & \\
\hline Yes & 7704 & 73.7 & 0.67 & $(0.58-0.78)$ & 0.57 & $(0.42-0.77)$ & 0.80 & $(0.63-1.01)$ \\
\hline \multicolumn{9}{|l|}{ Social class } \\
\hline I-II & 2539 & 26.0 & 1.00 & & 1.00 & & 1.00 & \\
\hline IIINM & 2412 & 24.7 & 1.28 & $(1.01-1.63)$ & 1.17 & $(0.71-1.94)$ & 1.41 & $(0.99-2.01)$ \\
\hline IIIM & 2052 & 21.0 & 1.75 & $(1.39-2.20)$ & 1.83 & $(1.14-2.93)$ & 1.58 & $(1.12-2.26)$ \\
\hline IV-V & 1762 & 18.1 & 2.26 & $(1.80-2.83)$ & 2.26 & $(1.41-3.61)$ & 2.03 & $(1.43-2.89)$ \\
\hline Other & 996 & 10.2 & 3.07 & $(2.41-3.90)$ & 2.69 & $(1.61-4.49)$ & 2.72 & $(1.87-3.96)$ \\
\hline \multicolumn{9}{|l|}{ Body mass index $\left(\mathrm{kg} \mathrm{m}^{-2}\right)$} \\
\hline$<20$ & 607 & 5.9 & 1.00 & & 1.00 & & 1.00 & \\
\hline $20-24.9$ & 5366 & 52.0 & 0.80 & $(0.60-1.05)$ & 1.39 & $(0.61-3.20)$ & 1.08 & $(0.68-1.72)$ \\
\hline $25-29.9$ & 3453 & 33.4 & 0.88 & $(0.67-1.17)$ & 2.26 & $(0.99-5.18)$ & 1.08 & $(0.67-1.73)$ \\
\hline$\geq 30$ & 902 & 8.7 & 0.90 & $(0.64-1.27)$ & 2.22 & $(0.89-5.52)$ & 0.63 & $(0.34-1.19)$ \\
\hline \multicolumn{9}{|l|}{ Alcohol intake } \\
\hline Never & 1976 & 19.3 & 1.00 & & 1.00 & & 1.00 & \\
\hline Light & 6849 & 67.0 & 0.58 & $(0.49-0.67)$ & 0.48 & $(0.34-0.66)$ & 0.70 & $(0.54-0.90)$ \\
\hline Moderate/heavy & 1393 & 13.6 & 0.84 & $(0.68-1.04)$ & 0.69 & $(0.44-1.08)$ & 0.83 & $(0.59-1.17)$ \\
\hline
\end{tabular}

Table 2 Relative risk (RR) (and 95\% confidence interval) of mortality from all causes, ischaemic heart disease (IHD) and cancer, associated with frequency of participation in vigorous physical activity as reported in the postal questionnaire, after adjustment for potential confounding factors $(n=10522)$

\begin{tabular}{lccc}
\hline & \multicolumn{3}{c}{ Vigorous exercise } \\
\cline { 2 - 4 } & Never/<1 time per month & $<2$ times per week & $\geq 2$ times per week \\
\hline$n(\%)$ & $8239(80.2)$ & $1030(10.0)$ & $1001(9.7)$ \\
All-cause mortality & & & \\
Deaths & 732 & 39 & 54 \\
RR (age- and sex-adjusted) & 1.00 & $0.57(0.42-0.79)$ & $0.72(0.54-0.95)$ \\
RR (fully adjusted) & 1.00 & $0.63(0.45-0.89)$ & $0.81(0.60-1.09)$ \\
IHD mortality & & & \\
Deaths & 155 & 6 & 13 \\
RR (age- and sex-adjusted) & 1.00 & $0.45(0.20-1.01)$ & $0.81(0.46-1.43)$ \\
RR (fully adjusted) & 1.00 & $0.46(0.19-1.12)$ & $0.96(0.53-1.75)$ \\
Cancer mortality & 308 & & \\
Deaths & 1.00 & $0.69(0.44-1.09)$ & $0.77(0.51-1.17)$ \\
RR (age- and sex-adjusted) & 1.00 & $0.72(0.44-1.18)$ & $0.91(0.59-1.42)$ \\
RR (fully adjusted) & & & \\
\hline
\end{tabular}

${ }^{*}$ Adjusted for age, sex, smoking status, alcohol consumption, pre-existing disease and social class. 
mortality, although the relationship was not significant at the 5\% level. Following adjustment for potential confounders, only the reduction in risk of all-cause mortality associated with participation in vigorous physical activity less than twice per week remained significant.

Table 3 shows the relationship between subsequent mortality and frequency of participation in physical activity as reported at the nurse health check. Participants who reported exercising vigorously at least once per week were at significantly lower risk of mortality from all causes compared with those engaging in this type of activity less than once per month. There was a similar pattern between frequency of vigorous physical activity and IHD and cancer mortality, although only exercising vigorously at least twice per week was associated with a significant reduction in risk of cancer mortality.

\section{Discussion}

The results of this study indicate that responses to simple questions regarding the frequency of participation in vigorous-intensity physical activity are associated with the risk of future mortality. Simple dietary questions have also been shown to predict mortality ${ }^{5}$. Respondents to the postal questionnaire who reported engaging in vigorousintensity physical activity less than twice per week experienced a $37 \%$ reduced risk of all-cause mortality compared with respondents who reported a lower frequency of vigorous physical activity. Similar, but not statistically significant reductions in risk were observed for IHD and cancer mortality. Those who reported a symptom history suggestive of IHD at baseline were excluded from these analyses.

Stronger relationships were found between selfreported physical activity and subsequent mortality for the further selected subset of participants who attended a nurse health check. We have previously shown that attendance at a health check was lower among people who rarely attended the surgery and among those who reported more risky health behaviours ${ }^{6}$, but the comparisons reported in Table 3 are limited to those people who attended a health check and so are unaffected by the selection of the cohort. Those participants who reported one occasion of vigorous-intensity physical activity per week experienced $47 \%$ lower all-cause mortality risk compared with participants who reported such activity less than once per month. Participants reporting more than one occasion per week of such activity had a similar reduction in risk (48\%). Only those participants who reported at least two occasions of vigorous exercise per week experienced a significant reduction in risk from cancer mortality, compared with those exercising at this intensity less than once per month. No statistically significant relationships were observed between selfreported exercise and IHD mortality, although it appeared to be lower in those exercising once per week or more.

Table 2 shows an apparent U-shaped curve for mortality in those reporting the greatest frequency of vigorous exercise. This observation has been reported in other cohort studies in the UK and USA ${ }^{7,8}$. These observations suggest that there may be an upper threshold for benefit from physical activity. A literature review of 44 studies reporting the dose-response in physical activity and allcause mortality only found five studies reporting a threshold effect, while the others reported a doseresponse relationship 9 . In the study reported here, the categories of physical activity considered represent less activity than many of the studies included in the review. In the review, typically, the category next to the referent group represented physical activity equivalent to $1000 \mathrm{kcal}$ week $^{-1}$ or approximately 3-5 exercise occasions per

Table 3 Relative risk (RR) (and 95\% confidence interval) of mortality from all causes, ischaemic heart disease (IHD) and cancer, associated with frequency of participation in vigorous physical activity as reported at interview, after adjustment for potential confounding factors in participants attending a health check $(n=7704)$

\begin{tabular}{|c|c|c|c|c|}
\hline & \multicolumn{4}{|c|}{ Vigorous exercise } \\
\hline & $<1$ time per month & $1-3$ times per month & 1 time per week & $\geq 2$ times per week \\
\hline $\begin{array}{l}\text { All-cause mortality } \\
\text { Deaths } \\
\text { RR (age- and sex-adjusted) } \\
\text { RR (fully adjusted)* }\end{array}$ & $\begin{array}{r}435 \\
1.00 \\
1.00\end{array}$ & $\begin{array}{c}22 \\
0.68(0.45-1.05) \\
1.14(0.74-1.78)\end{array}$ & $\begin{array}{c}28 \\
0.40(0.27-0.58) \\
0.53(0.35-0.82)\end{array}$ & $\begin{array}{c}32 \\
0.4(0.28-0.57) \\
0.52(0.35-0.78)\end{array}$ \\
\hline $\begin{array}{l}\text { IHD mortality } \\
\text { Deaths } \\
\text { RR (age- and sex-adjusted) } \\
\text { RR (fully adjusted) }\end{array}$ & $\begin{array}{l}96 \\
1.00 \\
1.00\end{array}$ & $\begin{array}{c}4 \\
0.84(0.31-2.28) \\
1.15(0.42-3.17)\end{array}$ & $\begin{array}{c}3 \\
0.30(0.09-0.94) \\
0.37(0.12-1.17)\end{array}$ & $\begin{array}{c}6 \\
0.44(0.20-1.02) \\
0.50(0.20-1.23)\end{array}$ \\
\hline $\begin{array}{l}\text { Cancer mortality } \\
\text { Deaths } \\
\text { RR (age- and sex-adjusted) } \\
\text { RR (fully adjusted) }\end{array}$ & $\begin{array}{r}181 \\
1.00 \\
1.00\end{array}$ & $\begin{array}{c}14 \\
1.45(0.84-2.51) \\
1.67(0.94-2.96)\end{array}$ & $\begin{array}{c}18 \\
0.85(0.52-1.38) \\
0.86(0.50-1.47)\end{array}$ & $\begin{array}{c}14 \\
0.53(0.31-0.92) \\
0.51(0.28-0.95)\end{array}$ \\
\hline
\end{tabular}

\footnotetext{
*Adjusted for age, sex, smoking status, alcohol consumption, pre-existing disease and social class.
} 
week ${ }^{9}$. Other studies have also found a protective effect with doses of exercise as low as once a week ${ }^{7}$. The inconsistent findings of these studies mean, therefore, that the question of an upper threshold remains unresolved.

Physical activity is difficult to measure with a high degree of precision, particularly the intensity of physical activity $^{10}$. Therefore, it is possible the observations in Table 2 represent misclassification of physical activity. The physical activity questionnaire used in this study had not been validated. One problem is that it asked respondents to report their frequency of participation in vigorousintensity physical activity, using guidance indicating that vigorous meant activities that made them out of breath and by giving examples of activities such as 'jogging, aerobics, football, tennis, etc.' There is a risk of overreporting using this approach as opposed to an approach where respondents simply report all activity and intensity is assigned at the coding stage using published tables ${ }^{11,12}$. Any resulting misclassification will be random and unrelated to mortality as physical activity was assessed prospectively. This would tend to attenuate the true relationship between physical activity and mortality.

It is also possible that residual confounding has affected the observed associations between physical activity and mortality, although many of the known confounders were controlled for.

\section{Conclusion}

When this questionnaire was designed, physical activity recommendations advocated vigorous-intensity physical activity for $20 \mathrm{~min}$ on at least 3 days of the week ${ }^{13}$. Since then the recommendations have been updated to include a recommendation for $30 \mathrm{~min}$ of moderate-intensity physical activity on most - preferably all - days of the week $^{14,15}$. The newer recommendations recognise that significant health benefits can be obtained with more frequent but lower-intensity patterns of physical activity. Future questionnaires, however short, will need to be able to capture physical activity of this nature.

This study provides some evidence that simple measures of physical activity can predict future mortality, at least all-cause mortality in a somewhat selected group. These observed associations between physical activity and mortality are congruent with those of many other observational studies. Nevertheless, the population of the UK, along with that of other Western countries, continues to have a high prevalence of physical inactivity ${ }^{2,16-18}$. There is a public health imperative to find effective ways of encouraging physical activity.

\section{Acknowledgements}

The authors gratefully acknowledge the contributions of the study participants and former OXCHECK collaborators. OXCHECK was funded by the former Imperial Cancer Research Fund.

\section{References}

1 US Department of Health and Human Services (DHHS). Physical Activity and Health: A Report of the Surgeon General. Atlanta, GA: DHHS, Centers for Disease Control and Prevention, National Center for Chronic Disease Prevention and Health Promotion, 1996.

2 Department of Health. Health Survey for England 1998. London: The Stationery Office, 2000.

3 Imperial Cancer Research Fund OXCHECK Study Group. Prevalence of risk factors for heart disease in OXCHECK trial: implications for screening in primary care. British Medical Journal 1991; 302: 1057-60.

4 Office of Population Censuses and Surveys. Classification of Occupations. London: HMSO, 1980.

5 Whiteman D, Muir J, Jones L, Murphy M, Key T. Dietary questions as determinants of mortality: the OXCHECK experience. Public Health Nutrition 1999; 2: 477-87.

6 Thorogood M, Coulter A, Jones L, Yudkin P, Muir J, Mant D. Factors affecting response to an invitation to attend for a health check. Journal of Epidemiology and Community Health 1993; 47: 224-8.

7 Shaper AG, Wannamethee G. Physical activity and ischaemic heart disease in middle-aged British men. British Heart Journal 1991; 66: 384-94.

8 Paffenbarger RS Jr, Hyde RT, Wing AL, Hsieh C. Physical activity, all-cause mortality, and longevity of college alumni. New England Journal of Medicine 1986; 314: 605-13.

9 Lee I-M, Skerrett PJ. Physical activity and all-cause mortality: what is the dose-response relation? Medicine and Science in Sports and Exercise 2001; 33(Suppl.): S459-71.

10 Duncan GE, Sydeman SJ, Perri MG, Limacher MC, Martin AD. Can sedentary adults accurately recall the intensity of their physical activity? Preventive Medicine 2001; 33: 18-26.

11 Lamonte MJ, Ainsworth BE. Quantifying energy expenditure and physical activity in the context of dose response. Medicine and Science in Sports and Exercise 2001; 33(Suppl.): S370-80.

12 Ainsworth BE, Haskell WL, Leon AS, Jacobs DR Jr, Montoye $\mathrm{JH}$, Sallis JF, et al. Compendium of physical activities: classification of energy costs of human physical activities. Medicine and Science in Sports and Exercise 1993; 25: 71-80.

13 American College of Sports Medicine position stand: the recommended quantity and quality of exercise for developing and maintaining cardiorespiratory and muscular fitness in healthy adults. Medicine and Science in Sports and Exercise 1990; 22: 265-74.

14 Department of Health. Strategy Statement on Physical Activity. London: Department of Health, 1996.

15 Pate RR, Pratt M, Blair SN, Haskell WL, Macera CA, Bouchard $\mathrm{C}$, et al. Physical activity and public health: a recommendation from the Centers for Disease Control and Prevention and the American College of Sports Medicine. Journal of the American Medical Association 1995; 273: 402-7.

16 Armstrong T, Bauman A, Davies J. Physical Activity Patterns of Australian Adults. Results of the 1999 National Physical Activity Survey. Canberra: Australian Institute of Health and Welfare, 2000.

17 Craig CL, Cameron C, Russell SJ, Beaulieu A. Increasing Physical Activity; Supporting Children's Participation. Ottawa: Canadian Fitness and Lifestyle Research Institute, 2001.

18 Centres for Disease Control. Physical activity trends - United States, 1990-1998. Morbidity and Mortality Weekly Report 2001; 50: 166-9. 


\section{Appendix}

\section{Baseline physical activity questions}

ON AVERAGE, how often do you undertake vigorous sport or recreational activities which make you breathless, e.g. JOGGING, AEROBICS, FOOTBALL, TENNIS, etc?

- Never or less than one day a month

- At least once a week but not every day

- One to three times a week

- More than three times a week
Supplementary physical activity questions (asked at interview)

During leisure hours, on average, how often do you undertake vigorous exercise, for example football, jogging, cycling, swimming?

- Less than once a month

- One to three times a month

- Once a week

- Twice a week or more 